\title{
IHTIOFAUNA LACULUI DE ACUMULARE DUBĂSARI - COMPOZIȚIA, DINAMICA MODIFICĂRILOR STĂRII CANTITATIVE ȘI CALITATIVE
}

\author{
Nicolae Șaptefrați, Dumitru Bulat, Marin Usatîi, \\ Denis Bulat, Ana Dadu, Aureliu Cebanu
}

Institutul de Zoologie, e-mail: bulatdm@yahoo.com

\section{Rezumat}

Lucrarea de față reprezintă rezultatele cercetărilor ihtiofaunei lacului de acumulare Dubăsari în aspect succesional. S-a constatat că în urma influenței factorilor antropici din ultimele 5 - 6 decenii (construcția barajelor Naslavcea și Novodnestrovsc, excavarea nisipului și pietrișului de râu din albia minoră, folosirea ireversibilă a apei în diferite scopuri, poluarea accidentală, biologică și termică, deteriorarea și distrugerea boiștilor pentru speciile litofile și fitofile ș.a.) în ihtiofauna cursului mijlociu al fl. Nistru (s. Naslavcea - Camenca) și lacului de acumulare Dubăsari au survenit modificări esențiale, acestea reflectându-se asupra stării structural-funcționale a populațiilor piscicole, ritmului de creștere, maturizării sexuale, prolificității și a ciclului sexual anual. În afară de acești factori care au influențat şi influențează în continuare negativ asupra resurselor piscicole din lacul de acumulare Dubăsari mai persistă şi gestionarea defectuoasă a lor în ultimii 25 ani.

Cuvinte-cheie: ecosistem, ihtiofaună, factori antropici, structură populațională, prolificitate.

\section{INTRODUCERE}

Lacul de acumulare Dubăsari este un ecosistem acvatic artificial amplasat pe fluviul Nistru având drept scop acumularea apei și folosirea ulterioară a resurselor acvatice în diverse activități. Se deosebește de fluviul Nistru printr-un șir de particularități: - schimbul de apă încetinit, specificitatea regimului hidrologic și termic, componenței și structurii faunei piscicole și a bazei trofice pentru pești.Începând cu anul 1954 Institutul de Zoologie a desfășurat și efectuează în continuare cercetări pentru evaluarea componenței structural-funcționale și modificării ihtiofaunei și elaborarea măsurilor ameliorativ-piscicole. De asemenea în scopul formării faunei piscicole pentru pescuit și a resurselor nutritive pentru pești, $\mathrm{s}$-au apreciat capacitățile adaptive ale populațiilor de pești în ecosistemul lacului de acumulare Dubăsari. S-au studiat procesele de re-

https://doi.org/10.53937/9789975151979.12

\begin{abstract}
This paperrepresents the results of the researches of the ichthyofauna of the Dubăsari accumulation lake in successional aspect. It was found that due to the influence of anthropogenic factors in the last 5-6 decades (construction of Naslavcea and Novodnestrovsc dams, excavation of sand and river gravel from the minor riverbed, use of water for various purposes, accidental, biological and thermal pollution, damage and destruction of substrate of reproduction for lithophilic and phytophilic species, etc.) in the ichthyofauna of the middle course of the Dniester River (Naslavcea - Camenca village) and the Dubasari accumulation lake have undergone essential changes, reflecting the structural and functional status of the fish populations, the growth rate, sexual maturation, prolificacy and the annual sexual cycle. Apart from these factors that have influenced and continue to negatively influence the fishery resources in the Dubasari reservoir, the factor of their poor management also persists in the last 25 years.
\end{abstract}

Keywords: ecosystem, ichthyofauna, anthropogenic factors, population structure, prolificacy.

producere naturală, creștere, structura populațiilor, dinamica loturilor pentru pescuit, proprietățile adaptive a faunei piscicole în condițiile acțiunilor factorilor abiotici specifici.

\section{METODE ȘI MATERIALE APLICATE}

Lucrarea de față reprezintă o analiză de sinteză a rezultatelor științifice multianuale a Laboratorului de Ihtiologie şi Acvacultură al Institutului de Zoologie privind starea ihtiofaunei lacului de acumulare Dubăsari, începând cu formarea sa și până în prezent.

De asemenea, la descrierea stocurilor piscicole din ecosistemul lacului, au fost utilizate rapoartele anuale ale Inspectoratului de Stat pentru protecția și reproducerea resurselor piscicole și reglementarea pescuitului. 


\section{REZULTATE OBȚINUTE ȘI DISCUȚII}

În fluviul Nistru în zona lacului de acumulare Dubăsari s-au remarcat 52 specii; [19,8], nemijlocit in lac, s-au constatat prezența și au descris particularitățile morfo-biologice a 47 specii de peşti dintre care 39 de specii habitau permanent în lac iar restul 8 specii de pești: chișcarul ucrainean, păstrăvul indigen, lipanul, știuca, cernușca, cosacul, morunașul și mihalțul se întẩlneau sporadic. În perioada anilor 19551959 au stabilit prezența a 42 specii [10]. În prezent, conform cercetărilor sistematice efectuate de către Institutul de Zoologie [1-5], ihtiofauna lacului de acumulare Dubăsari este formată din 47 specii.

După construirea barajului Dubăsari (a.1954) în lacul de acumulare format şi pe cursurile mijlociu si superior ale fluviului s-a format un ihtiocomplex specific cu dominarea plăticii, babuștei, salăului, crapului, cegii, morunașului, mrenei, somnului, cleanului, avatului, linului, știucii şi a altor specii valoroase de peşti $[15,16]$. Lacul de acumulare a devenit principalul loc pentru îngrășare a acestor specii iar cursurile mijlociu şi superior - locuri pentru reproducerea și dezvoltarea lor. Exploatarea resurselor piscicole din lac a început în a. 1958 și în primii ani capturile din pescuitul industrial constituia 90 tone [8]. Cantitatea de pește pescuită anual în lac (parțial și pe cursul mijlociu - tronsonul s. Goloșnița - or. Camenca) în perioada anilor 1960 - 1990 constituia circa 70 - 80 tone, iar în comun cu pescuitul sportiv/amatoristic peste 160 tone. Comparând ihtiofauna din momentul de față cu cea din perioada până la construirea barajului Dubăsari precum și cu cea imediat următoare după formarea lacului (aa. 1951-1960) constatăm modificări în dinamica și componența cantitativă și calitativă a faunei piscicole. În perioada anilor 1960-1970 dominante în pescuitul industrial au fost cosacul-cu-bot-turtit (29,71\%), bibanul (13,10\%), crapul (11,37\%), șalăul (9,13\%), plătica (8,75\%), avatul (4,45\%) și carasul argintiu (2,49\%). În perioada aa. 1980 - 1986 dominante sunt plătica (31,48\%), ocheana/babușca (27,32\%), șalăul (12,89\%) [4].

În perioada anilor 1965 - 1982 ponderea principalelor specii în productia piscicolă totală a crescut de la 30,3 t (52.4\%) până la 43,1 t (81\%). Aceasta s-a datorat faptului că $s$-au efectuat populări cu puiet mai calitativ și în cantități, reieșind din abundența și accesibilitatea bazei trofice, posibilitatea reproducerii naturale în condiții normale precum și diminuarea activităților economice din lac (interzicerea desfășurării lucrărilor de adâncire și excavare a nisipului și pietrei de râu în perioada de reproducere, interzicerea exploatării prizelor de captare a apei fără dispozitive de protecție a peștelui și mărirea dimensiunilor ochiurilor la sculele de pescuit (plase, ave, năvod, ietere) și alte activități [13].
După abundența relativă dintre speciile de talie mare în perioada existenței lacului predomină plătica $(3,4-26,7 \%)$, în prezent - 10,0\%, șalăul $7,0 \%$, avatul (0,3 - 3,62\%), în prezent - 2,2\%, crapul $(0,65-3,9 \%)$ în prezent $-3,9 \%$. Din speciile de talie mică și medie predomină babușca $(6,95-27,0 \%)$, în prezent - 13,8\%, cosacul-cu-bot-turtit $(2,9-12,7 \%)$ în prezent $-3,7 \%$. Dintre speciile fără valoare economică supremația este deținută de către obleț $(1,2$ - 17,20\%) în prezent - 1,2\%, bibanul (5,9-11,59\%), în prezent - $11,59 \%$ și ghiborțul $(0,1-9,02 \%)$, în prezent - 3,4\% [4]. După frecvență în lotul pentru pescuitul industrial începând cu a. 1981 predomină plătica - (29,5\%) și ocheana/babușca (23,8\%). În aa. 1983 și 1984 plătica ajunge la 29,1\% și babușca respectiv la 38,2\%. Din a. 1983 frecvența crapului scade până la 0,5\% și carasului argintiu până la 3,6\%. Somnul se întâlnește doar sporadic ponderea căruia în a. 1985 constituie doar 0,04\%. Acest fenomen de diminuare cantitativă și calitativă a resurselor piscicole care continuă până în prezent se produce din cauza mai multor factori antropici [4].

Unul din factorii principali care au contribuit la diminuarea cantitativă și calitativă a resurselor piscicole din lacul de acumulare Dubăsari este poluarea cu ape reziduale neepurate de la întreprinderile industriale și comunale, de la complexele zootehnice, cu erbicide, pesticide şi alte chimicale utilizate în agricultură spălate de pe terenurile agricole în timpul ploilor şi viiturilor pe parcursul ultimilor 50 - 60 ani, cauzând multiple modificări a condițiilor și calităților hidrobiologice, fizice şi fizico-chimice ale apei, provocând pieiri în masă a peștilor. Trebuie menționată poluarea din toamna anului $1983 \mathrm{cu} 4,5 \mathrm{mln} . \mathrm{m}^{3}$ ape reziduale (200 - $250 \mathrm{~g} / \mathrm{l}$ săruri de kaliu) deversate de la combinatul de îngrășăminte de kaliu din or. Stebnicov (Ucraina) în rezultatul căreia au pierit 920 tone pește marfă şi 1,3 tone puiet de pești. S-a diminuat abundența șalăului, novacului, sângerului, avatului, morunașului și a crescut abundența speciilor de talie mică (în deosebi a bibanului și a cosacului-cu-bot-turtit) [4]. În ansamblu are loc reducerea cantitativă a speciilor principale pentru pescuit.

Modificările semnificative ale abundenței puietului migrator au apărut din a. 1985 - odată cu începutul exploatării Nodului Hidrotehnic Dnestrovsc care a schimbat radical condițiile ecologice de funcționare a ecosistemelor cursului mijlociu al fluviului Nistru și lacului Dubăsari.

Analizând succesiunile multianuale a regimului termic s-a remarcat o scădere a temperaturii apei în perioada de primăvară - vară cu $5-8^{\circ} \mathrm{C}$, comparativ cu temperatura naturală, care se resimte până la barajul Dubăsari, provocând dependența inversă între volumul de apă deversat din lacul Novodnestrovsc şi temperatura apei pe o distanță de până la 400

„Modificări funcționale ale ecosistemelor acvatice în contextul impactului antropic și al schimbărilor climatice” 
km în aval. În perioada de iarnă temperatura apei este cu $5-6^{\circ} \mathrm{C}$ mai ridicată. Prin urmare în perioada de după construcția barajului Novodnestrovsc şi până în prezent s-a modificat substanțial dinamica distribuției temperaturilor medii anuale şi sezoniere a apei. Valorile maxime a temperaturilor de vară pe tronsonul s. Naslavcea - or. Camenca s-au deplasat cu o lună (o lună şi jumătate în anii mai răcoroși), de la mijlocul lunii iulie până la mijlocul lunii august fiind cu $4-5^{\circ} \mathrm{C}$ mai scăzute.

Diminuarea reproducerii naturale a speciilor principale de pești din complexul ihtiofaunistic din cursul mijlociu și lacul Dubăsari a influențat nemijlocit asupra stării resurselor piscicole în locurile de îngrășare. Conform pescuiturilor efectuate cu traulul pelagic în aa. 1987, 1988, 1996 s-a constatat că resursele piscicole în a. $1996 \mathrm{~s}$-au diminuat cu $96,2 \%$ sau de 26 ori iar a puietului de 44 ori. Speciile dominante au rămas plătica și ocheana/ babușca care constituie $88 \%$ din abundența totală, însă, comparativ cu abundența din a. 1987 ea s-a diminuat cu 95,0\% sau de 21 ori. Din cauza deversării apei reci din lacul Novodnestrovsk speciile fitofile nu mai folosesc boiștile din cursul mijlociu, iar suprafețele boiştilor din lacul Dubăsari sunt insuficiente. S-a redus reproducerea naturală nu numai a speciilor care se reproduc la temperatura apei de $15-22{ }^{\circ} \mathrm{C}$ (cegă, roșioară, morunaș, caras, crap, clean, caracudă, somn), dar şi a speciilor cu reproducere timpurie care se reproduc la temperatura apei de $4-15^{\circ} \mathrm{C}$ (avat, ocheană, știucă, biban, șalău, clean-mic, văduviță, plătică, babușcă, mreană, scobar). Prin urmare capacitatea reproductivă a loturilor de reproducători a scăzut semnificativ [17].

De asemeni și regimul de exploatare a hidrocentralei de la Novodnestrovsk care a redus considerabil debitul de apă în perioada de reproducere a peștilor (aprilie-iunie) cu 200,0 - 40,7 m³ $/ \mathrm{s}$, iar variațiile nictemere a nivelului apei (până la $1,5 \mathrm{~m}$ ) au stopat practic reproducerea speciilor fitofile, care constituie peste $50 \%$ din speciile prezente şi $90 \%$ din efectivul lor numeric. Până la edificarea barajului de la Novodnestrovsk, cursul mijlociu al fl. Nistru era locul de reproducere a peste 30 specii şi subspecii de peşti, însă după anul 1985, concomitent cu începutul exploatării complexului hidroenergetic a început să scadă numărul puietului pe boiști. Cercetările efectuate au constatat că principala influență negativă, - temperaturile scăzute ale apei în perioadele de primăvară - vară și ridicate în perioada de toamnă - iarnă, au acțiuni negative esențiale asupra proceselor de maturație și realizare a produselor sexuale și ca urmare se reflectă nemijlocit asupra efectivelor completării loturilor de reproducători și pentru pescuit iar diminuarea cantitativă a lor este progresivă și constantă.
După structura de vârstă a loturilor pentru pescuitul industrial a ocheanei, plăticii, crapului, carasului și șalăului după anul 1983 capturile erau formate din indivizii grupelor de recruți. Dacă în aa. 1981 - 1983 cea mai mare pondere în capturi o aveau grupele de vârstă de 5 - 6 ani, apoi în a. 1984 - 4-5 ani, iar în 1985, respectiv 3-4 ani. Loturile de reproducători a plăticii erau formate din indivizi de 2-6 ani iar în structura lor dominau indivizi de $3-4$ ani (64,0\%), raportul sexelor: - femele - 70\%; masculi - 30\%. Capturile, preponderent, erau reprezentate de indivizii de $3-4$ ani. Valorile gravimetrice variau de la 27 până la $43 \mathrm{~cm}$ și greutatea de la 435 până la $1500 \mathrm{~g}$ la masculi și de la 430 până la $1550 \mathrm{~g}$ la femele.

Valorile gravimetrice medii pentru pescuit au fost de $31 \mathrm{~cm}$ și greutatea $730 \mathrm{~g}$ la masculi și respectiv $32 \mathrm{~cm}$ și $840 \mathrm{~g}$ la femele [4].

După 10 - 15 ani de la formarea lacului de acumulare Dubăsari în rezultatul creșterii bruște a bazei trofice, adaptarea la condițiilor create din lac legată de capacitatea acestei specii de a folosi resursele de hrană bentonice la adâncimi de $4-5 \mathrm{~m}$, extinderea suprafețelor pentru reproducere și populărilor sistematice cu puiet, abundența populațiilor de plătică a crescut [6,7]. Capturile anuale a plăticii în a. 1974 au ajuns la 28,9 tone devenind specia reprezentativă din totalul capturilor.

Ulterior, în rezultatul colmatării, creșterii abundente a macrofitelor, poluărilor sistematice, etc., începe degradarea lacului. În apropiere de baraj stratul de nămol este de $12-15 \mathrm{~m}$ și începe să se diminueze biomasa bentosului, zonele cu adâncimi mici se acoperă cu vegetație iar supraviețuirea puietului timpuriu de plătică se diminuează $[12,18]$. De asemenea la diminuarea puietului influențează și concurența trofică cu puietul speciilor mai puțin valoroase (oblețul, cleanul-mic, babușcă, bibanul ș.a.) [16], abundența cărora odată cu degradarea lacului crește vertiginos iar abundența și capturile pescuitului industrial scad. În perioada anilor 1990 - 2019 abundența plăticii în lacul de acumulare Dubăsari s-a diminuat mai mult de 10 ori (calculând de la perioada de vârf aa. 70 secolul trecut), iar capturile pescuitului industrial/ comercial au ajuns mai puțin de 1 (una) tonă pe an. $\mathrm{S}$-au deplasat termenii de reproducere din perioada aprilie - mai în perioada mai - iunie. În prezent restabilirea populațiilor de plătică nu se mai poate realiza numai prin reproducerea naturală.

Loturile de reproducători a șalăului erau formate de indivizi de 3 - 9 ani. Baza loturilor de reproducători îl constituia indivizii de $4-5$ ani (58\%). Raportul sexelor era: 53\% femele și masculi $47 \%$. Bază loturilor pentru pescuit era formată din indivizi de 5 ani (33\%). Structura gravimetrică varia de la 26 până la $50 \mathrm{~cm}$. Masculii aveau dimen- 
siuni de la 26 până la $58 \mathrm{~cm}$ și greutatea de la 320 g până la $1550 \mathrm{~g}$, femelele respectiv de la 26 până la $50 \mathrm{~cm}$ și greutatea de la 326 până la 1680 g. Dimensiunile medii pentru pescuit a masculilor era de $39 \mathrm{~cm}$ iar a femelelor de $40 \mathrm{~cm}$. În primii ani după formarea lacului capturile de șalău au fost nesemnificative (între $0,1-3,3$ tone). În a. 1964 se înregistrează o creștere mai accentuată de 18,6 tone, apoi iarăși s-a înregistrat o creștere mai lentă a capturilor, diminuarea fiind legată de un sir de factori: conditii nefavorabile pentru reproducerea naturală, reglementarea ineficientă a pescuitului (pescuirea masivă a reproducătorilor în perioadele prereproductivă și de reproducere), migrarea puietului în timpul viiturilor de primăvară - vară în aval de baraj, fluctuațiile puternice a nivelului apei care condiționează condițiile de furajere a puietului la stadiile timpurii de dezvoltare). Începând cu anul 1979 resursele șalăului s-au stabilizat și până în a. 1981 iarăși capturile anuale a pescuitului industrial au variat de la 7,0 t până la 14,0 t. Dinamica populațiilor de șalău în această perioadă este legată de faptul că reproducerea naturală nu este prea mult deranjată de condițiile hidrologice fiindcă reproducerea lui începe înainte de producerea fluctuațiilor accentuate de nivel din primăvară, iar locurile lui caracteristice de reproducere nu sunt supuse pericolului de a rămâne pe uscat, în interval de $2-3$ zile, cum se întâmplă în cazul plăticii, crapului, carasului și a altor ciprinide.

Fluctuațiile cantitative ale populațiilor de șalău se observă chiar din primii ani de viețuire în condițiile lacului, adaptându-se la diverse temperaturi de reproducere, substrat și adâncimi de reproducere. Reproducerea salăului este extinsă după durată și limitele temperaturii apei de la $9-12^{\circ} \mathrm{C}$ până la $14-20^{\circ} \mathrm{C}$ și se desfășură în martie - mai (în prezent după a. 1985 aprilie - iunie). O parte a populației depune icre pe substratul cu vegetație tânără acoperită de apă. O altă parte a populației s-a adaptat la depunerea icrelor pe nisip la adâncimi de 1 - $2 \mathrm{~m}$ și cu curent slab. Asemenea adaptări asigurau anual o reproducere relativ eficientă, care concomitent cu populările cu puiet contribuiau la creșterea abundenței populațiilor de șalău.

Loturile de reproducători a crapului erau formate din indivizi de $3-8$ ani, predominate de indivizi de $4-5$ ani (60.9\%), raportul sexelor indivizilor maturizați: femele $-35 \%$ și masculi - 30\%, capturile erau dominate de indivizi de $3-4$ ani $(57,2 \%)$. Valorile gravimetrice variau de la 30 până la $70 \mathrm{~cm}$ : - masculii de la 30 până la $60 \mathrm{~cm}$ și greutatea de la 90 până la $4800 \mathrm{~g}$ iar femelele respectiv de la 30 până la $60 \mathrm{~cm}$ și greutatea de la 1000 până la $6000 \mathrm{~g}$. Lungimea medie pentru pescuit la masculi constituia $40,5 \mathrm{~cm}$ cu greutatea de $1600 \mathrm{~g}$ și la femele
$43 \mathrm{~cm}$ și greutatea de $1800 \mathrm{~g}$. În aspect succesional dinamica ponderii crapului din lacul de acumulare Dubăsari la constituirea producției piscicole totale a avut modificări sesizabile, capturile fiind cuprinse între 2,2 t în aa. 1960, 1982 și 15,7 t în a. 1970. În perioada aa. 1969 - 1980 captura medie anuală este de 7,6 (cele mai mari capturi realizându-se în aa. 1970 - 15,7 t; 1971 - 11,5t; 1974 - 10,8 t și $1975-9,1$ t). În perioada imediat următoare după începutul exploatării Nodului Hidrotehnic Novodnestrovsc (1983) capturile scad brusc până la 0,6 t, apoi după 1987 urmează iarăși o creștere a capturilor (aa. 1987 - 8,7 t; 1988 - 12,3 t; 1989 - 7,9 t; 1990 - 8,0 t și 1991 - 4,0 t). După a. 1992 și până în prezent capturile anuale nu depășesc $0,5-1,0$ t. Diminuarea producției piscicole de crap din lacul Dubăsari este determinată de următorii factori: deranjarea reproducerii naturale de către fluctuațiile nivelului apei în perioada de reproducere; - deteriorarea și distrugerea suprafețelor pentru reproducerea naturală; - neefectuarea măsurilor de ameliorare piscicolă (popularea cu puiet calitativ și în cantități necesare, instalarea cuibarelor artificiale, asigurarea regimului hidrologic prielnic reproducerii naturale ș.a.); - lipsa unei evidențe clare a pescuitului industrial/comercial și sportiv/ amatoristic din partea organelor pentru protecția mediului; - braconajul și înstrăinarea pe diverse căi a unei părți importante de crap din lac.

Loturile de reproducători a carasului argintiu erau formate din indivizi de $3-9$ ani, dominau indivizii de $4-5$ ani (72\%), raportul sexelor: femele -55 $\%$; masculi $-45 \%$. Lotul pentru pescuit era format din indivizi de $5-6$ ani (50\%). Lungimea varia de la 19 până la $35 \mathrm{~cm}$, raportul sexelor: femele $-57 \%$ si masculi $-43 \%$. Lungimea medie pentru pescuit la masculi era de $27 \mathrm{~cm}$ și la femele $28 \mathrm{~cm}$. Greutatea medie la masculi - 1890g și la femele - 1940g.. Aportul carasului argintiu în producția piscicolă din lac până în a. 1970 a fost nesemnificativă și nu a avut nici o importanță în economia pescuitului industrial. Treptat abundența populațiilor de caras argintiu a început să crească datorită potențialului adaptiv înalt, îmbunătățirii condițiilor de reproducere (concomitent cu creșterea abundenței populațiilor de plătică și crap - partenerii lui în reproducerea ginogenetică, dar și în urma populărilor efectuate de către gospodăria piscicolă Nistreană (s. Oxentia). Din a. 1970 de la 5,6 t capturate, cantitatea pescuită a ajuns până la 10,1 t în a. 1971; 17,3 t - a. 1972;21,9 t - a. 1973; 20,3 t - a. 1974; 24,0 t - a. 1975; 20,0 t a. 1976; 6,9 t în a. 1979. Apoi urmează o diminuare 3,3 t în a. 1980 și 1,4 t în a. 1984. Aceste fluctuații $(0,7-6,0$ t) continuă până în prezent.

Loturile de reproducători a ocheanei (tarancă) erau formate din indivizi de 3 - 9 ani. Baza captu- 
rilor era dominată de indivizi de 5 ani (34\%), raportul sexelor: femele $-51 \%$, masculi $-49 \%$. Lotul pentru pescuit era dominat de indivizi de 5 ani (34\%). Lungimea varia de la 21 până la $30 \mathrm{~cm}$, raportul sexelor: femele $-52 \%$, masculi $-48 \%$. Lungimea medie pentru pescuit era de $25 \mathrm{~cm}$ la masculi și $28 \mathrm{~cm}$ la femele. Greutatea medie la femele - $594 \mathrm{~g}$ și masculi - 412g. În primii ani după formarea lacului ocheana se întâlnea în cantități foarte mici - doar 0,02\% din capturile totale. Începând cu a. 1959 ponderea ocheanei brusc a crescut - 3,78\% după abundență și 6,13\% după greutate. Aceasta ne confirmă faptul că în lac s-au creat condiții favorabile pentru reproducere și îngrășare. Ponderea ocheanei în pescuitul industrial/comercial până în a. 1975 era de $0,1-1,0$ t. Din a. 1976 capturile ocheanei au crescut de la 6,6 t. (a. 1976) până la 10,8 t. (a. 1981).

\section{CONCLUZII}

Cercetările efectuate au constatat că influența factorilor antropici în ultimele 5 - 6 decenii (construcția barajelor Naslavcea și Novodnestrovsc, excavarea nisipului și pietrișului de râu din albia minoră, folosirea ireversibilă a apei în diferite scopuri, poluarea accidentală, biologică și termică, deteriorarea și distrugerea boiștilor pentru speciile litofile și fitofile ș.a.), în ihtiofauna cursului mijlociu al fl. Nistru (s. Naslavcea - Camenca) și lacului de acumulare Dubăsari au survenit modificări esențiale, acestea reflectându-se asupra structurii şi valorilor numerice a populațiilor, structurii de vârstă, ritmului de creștere, maturizării sexuale, prolificității și a ciclului sexual anual. În afară de acești factori care au influențat şi influențează în continuare negativ asupra resurselor piscicole din lacul de acumulare Dubăsari mai persistă şi gestionarea defectuoasă a lor în ultimii 25 ani (lipsa totală a evidenței clare și sistematice a pescuitului industrial/comercial şi sportiv/amatoristic, lipsa acordului de exploatare în comun cu Ucraina a resurselor biologice acvatice, necoordonarea acțiunilor în domeniul protecției şi folosirii raționale a resurselor piscicole cu raioanele din stânga Nistrului, ineficiența măsurilor de ameliorații piscicole, stabilirea cotelor pentru pescuitul industrial/comercial și sportiv/amatoristic, științific neargumentate, popularea numai cu puieți necalitativi de fitofagi și în cantități foarte mici, braconajul şi alte acțiuni).

În prezent în rezultatul micșorării temperaturii apei termenii de reproducere la majoritatea speciilor s-au deplasat până în iunie-iulie (iar în anii răcoroși până în august).

Regimul termic din cursul mijlociu al fluviului Nistru şi lacul de acumulare Dubăsari, condițiile ecologice nefavorabile și alți factori antropici, au afectat starea structural-funcțională a ihtiofaunei:
- s-a produs o întârziere a termenilor maturației sexuale la majoritatea speciilor valoroase de pești: șalăul se maturizează la vârsta de 4 - 5 ani; plătica - la 5 ani; babuș$c a$, ocheana - la 4 ani. Maturizarea sexuală are loc la o masă corporală mai mică;

- la reproducătorii speciilor valoroase de peşti s-a înregistrat o deplasare a perioadei de maturare sexuală şi a termenilor calendaristici de depunere a pontei într-un interval de timp mai redus, fapt care condiționează o reducere a perioadei de dezvoltare a puietului;

- la majoritatea femelelor (50-90\%) s-au evidențiat diverse schimbări morfofuncționale. La cca. 50 - 60\% din femelele speciilor valoroase de peşti, toamna (septembrie-octombrie) s-a constatat ovare în stadiul IV de maturiție cu numeroase oocite nedepuse,fiind în stare de resorbţie.

\section{RECOMANDĂRI}

Pentru conservarea diversității faunei piscicole în cursul mijlociu al fl. Nistru, și lacul de acumulare Dubăsari, păstrarea ihtiogenofondului speciilor valoroase, rare şi a celor pe cale de dispariție, ameliorarea structural - funcţională a populaţiilor pentru pescuit, restabilirea loturilor de reproducători, menținerea şi îmbunătățirea condițiilor favorabile de reproducere naturală, creștere şi îngrăşare a faunei piscicole din ecosistemele acvatice naturale în perioada anilor 2020 - 2030, Institutul de Zoologie recomandă efectuarea următoarelor măsuri de ameliorare piscicolă:

1. Restabilirea şi extinderea suprafeţelor boiştilor pentru reproducerea naturală a speciilor valoroase de peşti din cursul mijlociu, a lacului de acumulare Dubăsari, instalând anual cuiburi artificiale pentru depunerea icrelor în lac (8 10 mii buc.).

2. Crearea unui centru experimental pentru reproducerea speciilor valoroase de pești, formarea loturilor de reproducători a speciilor incluse in Cartea Roșie a Republicii Moldova (ediția a III-ea) şi a celor periclitate. Popularea anuală a lacului cu puiet în următoarea formulă: puiet (alevini) predezvoltat de şalău - 11 mln; plătică - 21,5 mln.; ocheană (tarancă) 21,5 mln.; morunaş - 5,5 mln.; mreană comună - 5,5 mln.; puiet de o vară de sânger - 1 mln.; novac - 1 mln.; cosaş - 250 mii; cegă - 100 mii; crap - 500 mii exp; caras-argintiu - 300 mii;

3. Organizarea şi efectuarea sistematică a pescuitului ameliorativ al speciilor economic nevaloroase (biban, obleţ, babuşcă, roşioară, ș.a.) reieșind din repartizarea cantitativă spaţio-temporală 
a lor în termenii şi condițiile recomandate de către instituțiile științifice în domeniu.

4. Ameliorarea (spălarea) boiştilor de resturile plantelor din anul trecut prin asigurarea unui flux de apă din lacul Novodnestrovsc cu un debit de $700-800 \mathrm{~m}^{3} / \mathrm{s}$ pe un termen de $4-5$ zile în perioadă imediată după desfundarea şi dezghetarea fluviului Nistru.

5. În scopul creării condițiilor favorabile pentru reproducerea naturală eficientă pe cursul mijlociu al Nistrului în aval de lacul de acumulare Novodnestrovsc de asigurat anual un regim hidrologic stabil (în perioada aprilie - iunie).

6. Anual în funcție de condițiile hidrologice și climaterice de extins perioadele de prohibiţie (cu 20 -30 zile) a pescuitului comercial şi sportiv/ amator în lacul Dubăsari pentru asigurarea reproducerii naturale mai eficientă a speciilor valoroase de peşti.

7. Desfășurarea cercetărilor științifice și observațiilor ihtiologice permanente în vederea evaluării stării actuale şi de perspectivă a resurselor piscicole, specificarea şi corectarea anuală a măsurilor de ameliorare piscicolă care urmează a fi efectuate.

Investigatiile au fost realizate în cadrul proiectului 20.80009.7007.06 "Determinarea schimbărilor mediului acvatic, evaluarea migrației și impactului poluanților, stabilirea legităților funcționării hidrobiocenozelor și prevenirea consecințelor nefaste asupra ecosistemelor”, finanțat de Agenția Națională pentru Cercetare și Dezvoltare din Republica Moldova.

\section{BIBLIOGRAFIE}

1. BULAT, DM. Ihtiofauna Republicii Moldova: amenințări, tendințe și recomandări de reabilitare. Chișinău: Foxtrod, 2017. 343 p. ISBN 978-9975-89-070-0.

2. BULAT DUMITRU. Ihtiofauna Republicii Moldova: Geneza, Starea Actuală, Tendințe și Măsuri de Ameliorare. Rezumatul tezei de doctor habilitat în științe biologice. Chișinău, 2019. 68 p.

3. BULAT, DM., BULAT, DN., TODERAȘ, I., USATÎI, M., ZUBCOV, E., UNGUREANU, L. Biodiversitatea, Bioinvazia și Bioindicația (în studiul faunei piscicole din Republica Moldova). Chișinău: Foxtrod, 2014. 430 p. ISBN 978-9975-120-38-8.

4. Rapoarte anuale ale Inspectoratului de Stat pentru protecția și reproducerea resurselor piscicole și reglementarea pescuitului (1955-1955, 1993-2008).

5. USATÎI, A., USATÎI, M., TODERAȘ, I., ȘAPTEFRAȚI, N. ATLAS: "Peștii apelor Moldovei". Academia de Științe a Moldovei, Institutul de Zoologie. - Chişinău: S. n., 2015 (F.E.-P. “Tipografia Centrală”). - 192 p. ISBN 978-9975-53-578-6. CZU 597.2/.5(478)(03) P 53.

6. БРУМА И.Х. Сохраним рыбные запасы. Кишинев: Картя молдовеняскэ, 1976.

7. БРУМА, И.Х., ВЛАДИМИРОВ, М.З. Рыбные запасы естественных водоемов Молдавий, их охрана и воспроизводство. Охрана природы Молдавий, Вып. 10, Изд.-во «Штиинца», 1972, с. 11-19.

8. БУРНАШЕВ, М.С., ЧЕПУРНОВ, В.С., ДОЛГИЙ, В.Н. Рыбы и рыбный промысел р. Днестр. В: Ученые записки Кишиневского государственного универсиmema, 1954, T. XIII, c. 17-40.

9. БУРНАШЕВ, М.С., ЧЕПУРНОВ, В.С., РАКИТИНА, Н.П. Рыбы Дубоссарского водохранилища и вопросы развития рыбного промысла в нем. В: Ученые записки Кишиневского Государсвенного Университета, 1955, T. 20, с. 25-37.

10. БЫЗГУ, С.Е., ДЫМЧИШИНА-КРИВЕНЦОВА, Т.Д., НАБЕРЕЖНЫЙ, А.И., ТОМНАТИК, Е.Н., ШАЛАРЬ, B.М., ЯРОШЕНКО, М.Ф. Дубоссарское водохранилище (Становление и рыбохозяйственное значение). Изд. Наука, Москва, 1964, 230 с.

11. ДОЛГИЙ В.Н. Ихтиофауна бассейнов Днестра и Прута. Кишинев: Штиинца, 1993.- 322 с.

12. ЗЕЛЕНИН А.М. Характер размножения леща в Дубоссарском водохранилище //Труды Института биологии МАФН СССР, 1960. -m. 2., выn. 1.- c. 42-49.

13. КОЖОКАРУ, Е.В., ПОЯГ, М. А. Рыбохозяйственное использование водных ресурсов Молдавий. Изд. ЦК КП Молдавии, Кишинев, 1973, 207 с.

14. ПОПА, Л.Л. Рыбы Молдавии. Справочник - определитель. Изд. Картя Молдовеняскэ. Кишинев, 1977, 200 c.

15. ТОМНАТИК Е.Н. Ихтиофауна водохранилища, ее изменение и пути увеличения запасов промыслово-ценных рыб. Дубоссарское водохранилище. Изд. Наука. Москва, 1964. с. 175-209.

16. ТОМНАТИК Е.Н. Направление формирования ихтиофауны Дубоссарского водохранилища в первые два года его становления. Изв. Молд. филиала АН СССР, 1958. №8(41), c. 67-81.

17. ТОМНАТИК Е.Н., БАТЫР А.К. Плодовитость леща Дубоссарского водохранилища. «Биологические ресурсы водемов Молдавии». Вып. 7, 1970, с. 107-115.

18. ЧЕПУРНОВА, Л.В. Закономерности функции гонад, размножения и состояния популяций рыб бассейна Днестра в условиях гидростроительства. Изд. Штиинца. Кишинев, 1991. 163 с. ISBN 5-37601037-6

19. ШАРАПАНОВСКАЯ, Т. Экологические проблемы Среднего Днестра. Экологическое общество «Biotica». Кишинэу, 1999, 88 с. ISBN 9975-78-025-3

20. ЯРОШЕНКО, М.Ф. Гидрофауна Днестра. Изд. АН СССР. Москва, 1957, 169 с. 